\title{
COBERTURA VEGETAL DO DISTRITO DE MACUCO, MUNICÍPIO DE SÃO DOMINGOS DO PRATA/MG
}

\author{
Mitzi Brandão 1 \\ Manuel Losada Gavilanes 2 \\ Vera Lúcia Gomes Klein ${ }^{3}$ \\ Lúcia Helena de Souza Cunha ${ }^{4}$
}

\begin{abstract}
RESUMO - Efetuou-se o levantamento da cobertura vegetal existente no Distrito de Macuco, Município de São Domingo do Prata, MG, como parte de um estudo detalhado das microbacias do Estado de Minas Gerais. A área sob enfoque era anteriormente recoberta pela Floresta Latifoliada Tropical Baixo Montana. Atualmente, a cobertura primitiva acha-se reduzida a capões esparsos, dispostos ao longo dos vales dos afluentes menores do Rio Macuco, ou então na cumiada dos morros mais altos, entremeada de pequenas áreas com culturas de subsistência, de pastagens, de capoeiras e de campos antrópicos. A composição botânica dos capões remanescentes, das capoeiras e dos campos antrópicos, soma 372 espécies, englobadas em 87 familias e 222 gêneros.
\end{abstract}

Palavras-chave: Composição Florística, Cobertura vegetal, Estado de Minas Gerais.

\begin{abstract}
Vegetation of Macuco town, São Domingos do Prata county, State of Minas Gerais, Brazil). This research surveyed the vegetation existent in Macuco Town, São Domingos do Prata county, state of Minas Gerais, Brazil, as part of a more detailed study of the microhydrobiological basins of this state. The area in study was previously covered with Latifoliated Tropical Forest. Recently the primitive vegetation is reduced to thickets scattered along the valleys of minor tributary streams of Macuco River or on hill tops intermixed by small areas cultivated with subsistence crops, pastures, brush, and fields. The botanical composition or remaining thickets, brushes and fields are represented by. 372 species, envolved in 87 families and 22 genres.
\end{abstract}

Key words: Floristic composition, Vegetation, State of Minas Gerais.

\section{Introdução}

A Empresa de Pesquisa Agropecuária de Minas Gerais (EPAMIG) vem desenvolvendo um projeto que visa ao estudo de "Unidades-Modelos", escolhidas em regiões diversificadas em termos de solo, vegetação e clima, dentro das quais serão desenvolvidos projetos agropecuários, os mais distintos, cujos resultados serão posteriormente extrapolados, para regiões similares dentro do Estado.

Foi escolhida como primeira unidade o distrito de Macuco, situado no Município de São Domingos do Prata, MG.

A área sob enfoque situa-se na、Microrregião 183 (Siderúrgica), aproximadamente no paralelo $19^{\circ} 58^{\prime}$ de latitude sul e a $42^{\circ} 48^{\prime}$ de longitude a oeste de Greewich (Figura) 1), cobrindo cerca de 2550 ha, apresentando relevo de ondulado a fortemente ondulado.

A sua cobertura vegetal primitiva era constituída pela Floresta Latifoliada Tropical Baixo Montana (Rizzini 1963) que, hoje, encontra-se intensamente devastada, estando praticamente reduzida a capões esparsos, nas cumeadas das elevações ou ao longo dos

1 Pesquisador da EPAMIG, Caixa Postal 515, 30.000 - Belo Horizonte (MG) Bolsista do CNPq.

2 Professor de Botânica da ESAL, Caixa Postal 37, 37.200 - Lavras (MG) Bolsista do CNPq.

3 Jardim Botânico do Rio de Janeiro

4 Pesquisador da EPAMIG, 30.000 - Belo Horizonțe, MG. Caixa Postal 515 
vales. A maior parte da área acha-se ocupada por pastagens onde predomina o capimgordura (Melinis minutiflora Beauv.), por campos antrópicos, capoeiras e capoeirões e, áreas esparsas de cultura de subsistência, como o milho, arroz e feijão, raramente outras, situadas em vários pontos do relevo, notadamente, nas baixadas.

No presente trabalho, pretende-se o estudo da cobertura vegetal, um dos ítens básicos a serem estudados, cabendo a outras equipes o desenvolvimento dos outros ítens que, posteriormente, serão correlacionados em um trabalho comum.

\section{Material e Métodos}

Foram realizados visitas bimensais, durante dois anos consecutivos, ao local de trabalho, tendo por objetivo, além da anotação de dados, a coleta de espécies ocorrentes na área, as quais foram colhidas, pensadas, etiquetadas e identificadas, achando-se hoje depositadas no PAMG (Herbário da Empresa de Pesquisa Agropecuária de Minas GeraisEPAMIG, Belo Horizonte, MG).

Em virtude da cobertura vegetal, outrora existente em toda a área, encontrar-se intensamente devastada, as coletas foram concentradas nos capões, capoeirões e capoeiras que ainda continham as espécies remanescentes. Foi também dada ênfase aos campos antrópicos, resultantes da retirada da cobertura vegetal primitiva e posterior cultivo.

As espécies coletadas foram ordenadas segundo suas famílias e gêneros, e apresentadas em listagens anexas. Somente as espécies que se encontravam férteis é que foram incluídas nas listagens.

\section{Resultados e Discussão}

Foram coletadas 372 espécies vegetais, englobadas em 87 famílias, compondo 222 gêneros, nas seguintes formações: Floresta Latifoliada Tropical Baixo Montana (capões esparsos), capoeiras em fases diversas de recuperação, campos antrópicos e várzeas.

$\mathrm{Na}$ Tabela 1 são relacionadas as espécies de plantas vasculares sem sementes, conforme o sistema de Crabbe et al. (1975).

$\mathrm{Na}$ Tabela 2 são listadas as espécies de plantas vasculares com sementes.

Nas áreas florestais, a composição florística é pobre, as árvores remanescentes, de pequeno diâmetro, sendo raras as epífitas. $\mathrm{O}$ estrato arbóreo mais alto raramente ultrapassa os 20,0m de altura, sendo constituído por poucas árvores; o estrato imediatamente inferior é mais rico e mais denso. São inúmeros os arbustos escandentes e as trepadeiras mais delicadas, havendo grande incidência de exemplares dos gêneros Chusquea e Merostachys que, muitas vezes, bloqueiam o acesso ao interior dos capões. O estrato herbáceograminoso só se mostra presente na orla da mata e ao redor das clareiras, sendo rico em Pteridófitas e Ciperáceas e pobre em gramíneas. Representantes do gênero Cecropia, em alguns capões, são bastante freqüentes e raros os exemplares de Euterpe edulis Mart. De maneira geral, as madeiras de lei já se mostram pouco freqüentes em toda a área, sendo raros os exemplares bem desenvolvidos pertencentes a esse grupo.

A fitofisionomia das áreas estudadas varia de acordo com a estação do ano.

No primeiro trimestre do mesmo, nas matas e capoeiras a tonalidade dominante de floração fica entre o branco e o roxo, pela concentração das acácias, angicos, jacarés, canelas e quaresmeiras, interrompida por manchas prateadas da folhagem das embaúbas. São padronizadoras as espécies: Acacia plumosa Lowe, Anadenanthera macrocarpa (Benth.) Brenam., Nectandra myriantha Meissn., Ocotea pretiosa (Nees) Mez., Piptadenia communis Benth., Tibouchina estrellensis (Raddi) Cogn., Cecropia hololenca Mart. (Navarro de Andrade \&.Vecchi 1916). 
No segundo trimestre, as manchas ralas e amarelas dos paus-de-tucano, róseas e brancas das paineiras e dos ingás, vão sendo paulatinamente substituídas por aquelas amarelas, muito densas e brilhantes, dos ipês e das cássias, de julho a setembro. Assim temos Vocnysia tucanorum Mart., Chorisia speciosa St. Hil., Cordia trichotoma (Vell.) Arrab., Inga fagifolia Willd., Tabebuia serratifolia (Vahl) Nichols., Cassia ferruginea Schrad. e Cassia macranthera DC.

Novamente essas manchas alteram-se com a chegada da primavera por aquelas brancas e roxas, representadas pelas caviúnas, pelos jacarandás, pelos cedros, pelos chichás e açoita-cavalos. Mostram-se então freqüentes: Dalbergia villosa Benth., Macchaerium aculeatum Raddi, Cedrela fissilis Vell., Sterculia chicha ST. Hil. e Luehea divaricata Mart. (Rizzini 1971).

Já nos campos antrópicos essa mudança na paisagem é menos acentuada, devido ao pequeno porte e pequenez das flores dessas plantas, exceção feita aos períodos de floração dos alecrins e dos assa-peixes, cujas populações densas mancham os campos de branco (Baccharis dracunculifolia DC.) e roxo (Vernonia ferruginea Less., Vernonia polyanthes Less. e Vernonia scorpioides (Lam.) Pers.).

Nas várzeas, dependendo dos meses do ano e da sucessão de culturas implantadas, o verde intenso e o verde claro são substituídos pelo pardo e o amarelo das plantas prontas para a colheita.

Apenas nas pastagens a monotonia se impõe, com o verde escuro ou o roxo intenso do capim-gordura, nas suas faces vegetativa e/ou reprodutiva.

\section{Conclusões}

Sendo a área sob enfoque extremamente declivosa, já estando em processo acentuado de erosão laminar e, em alguns locais de vaçorocas em estado adiantado de instalação, fato este agravado pelas classes de solos existentes, aconselha-se que se refaça rapidamente o reflorescimento local, restringindo-se as atividades agropecuárias àquelas áreas mais planas. As espécies empregadas no reflorestamento deverão ser aquelas já ocorrentes na própria área, ligadas aos gêneros Aspidosperma, Tabebuia, Cybistax, Chorisia, Cordia, Nectandra, Ocotea, Cariniana, Lecythis, Anadenanthera, Apuleia, Cassia, Inga, Erythrina, Machaerium, Petophorum, Piptadema, Cedrela, Cabralea, Luehea, Vochysia, Trema, entre outros citados por Ferreira \& Gavilanes (1981).

Nas áreas não muito declivosas o cultivo de plantas perenes, produtoras de fruto édulos, como: manga, abacate, fruta do conde, carambola, citrus, mamão, groselha, jaboticaba, etc., poderia ser incentivado, desde que o solo fosse protegido por cobertura herbáceo-graminosa (Garcia 1953). A consorciação dessas fruteiras poderia ser feita com leguminosas de pequeno porte dos gêneros Stylosanthes, Zornia, Desmodium, Calopogonium, Centrosema, que, além de fixadoras naturais de nitrogênio ao solo, também serviriam de contenção à erosão do mesmo.

O reflorestamento com as espécies nativas, próprias da área, ou o cultivo de frutíferas arbóreas com respectiva cobertura de solo, contribuiriam para o controle à erosão, enriquecimento das camadas superficiais do solo, melhoria das suas propriedades físicas, ativação da micro-fauna e micro-flora, regularização da vazão das águas pluviais, etc., conforme preconizou Galeti (1931), criando condições para a recuperação dos solos locais.

\section{Referências Bibliográficas}

CRABBE, J. A; JERMY, A.C. \& MICKEL, J.T. 1975. A new sequence for the pteridophyte herbarium. Fern. Gaz, 11(2-3): 141-162. 
FERREIRA, M. B \& GAVILANES, M. L. 1981 Reintrodução de essências nativas na recomposição das formações naturais, Inf. Agropec: Belo Horizonte, 7 (807: 50-58.

GALETI, P.A. 1931 Conservação do solo; reflorestamento, clima Campinas, ICEA, 286 p.

GARCIA, J. 1953. Protejamos nossas terras contra a erosão. Bol. Agric., 2(7-8): 13-16.

NAVARRO DE ANDRADE, E. \& VECCHI, O 1916 Les Bois Indigènes de São Paulo.

São Paulo, Secretarie de L'Agriculture Commerce et Travanx.

RIZZINI, C. T. 1963. Nota prévia sobre a divisão fitogeográfica do Brasil. Rev. Bras.

Geogr., 25(1): 3-64

RIZZINI, C.T. 1971. Árvores e Madeiras úteis do Brasil. São Paulo, E. Blucher. 294.

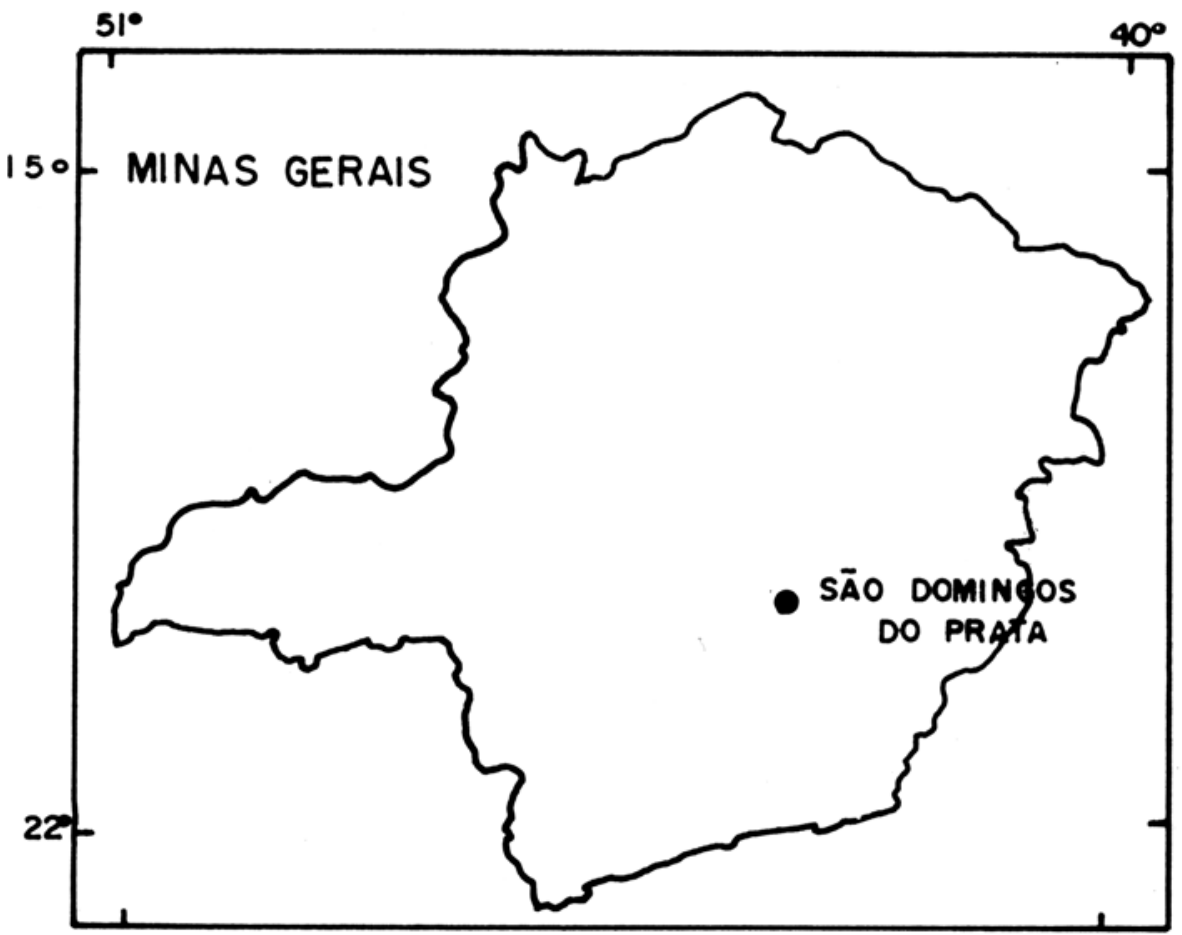

Figura 1. Localização do Município de São Domingos do Prata,Minas Gerais. 


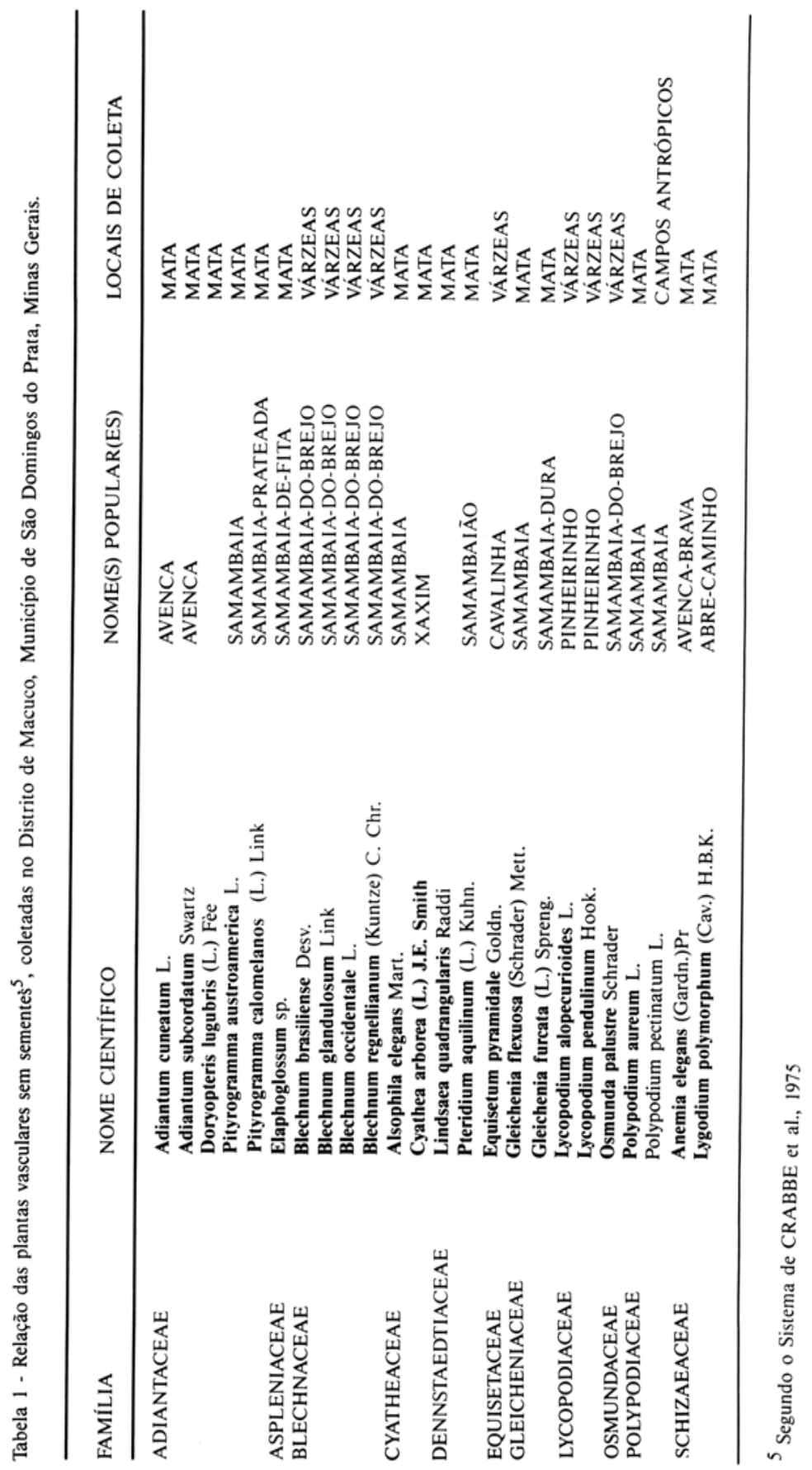




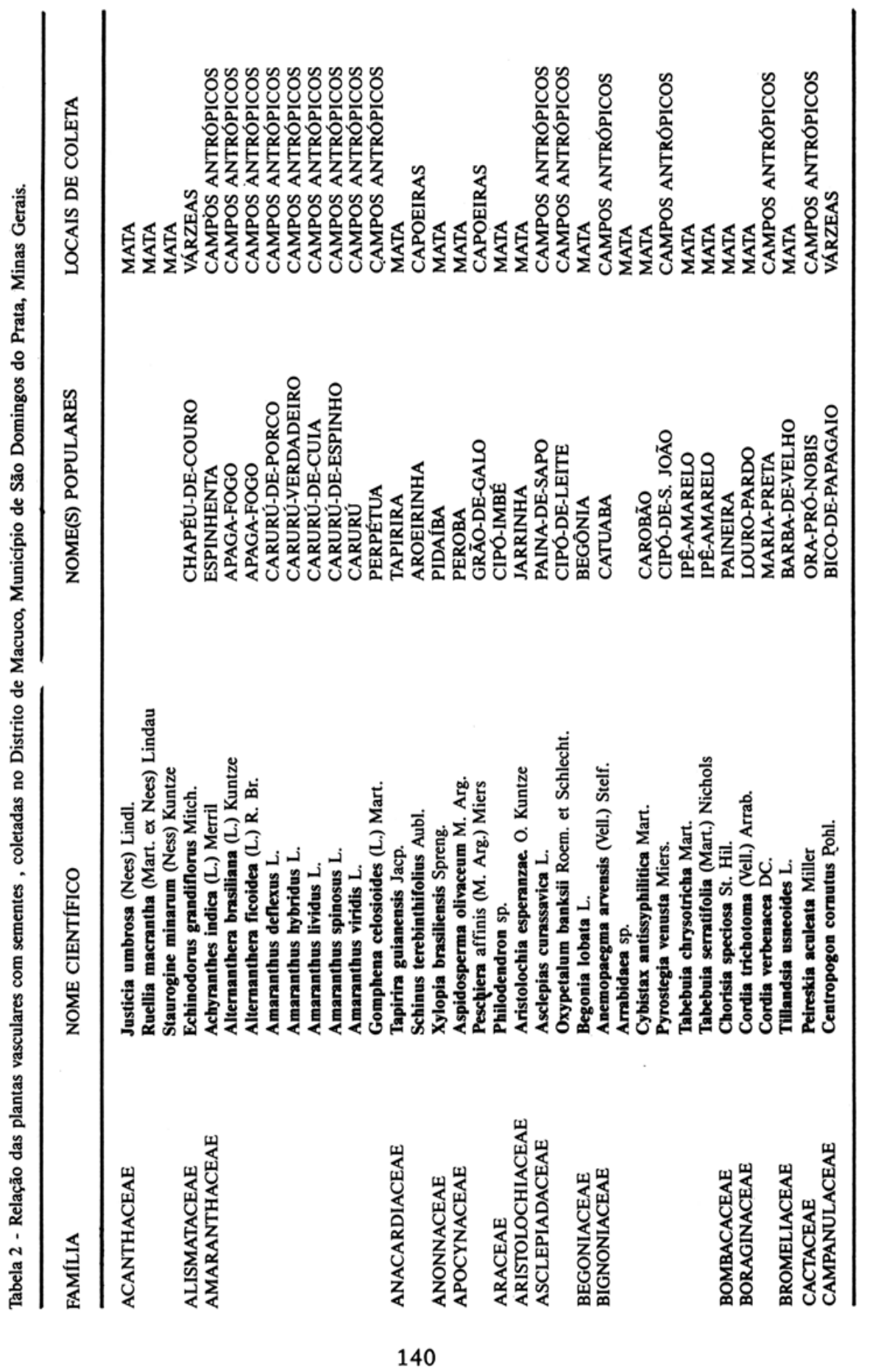




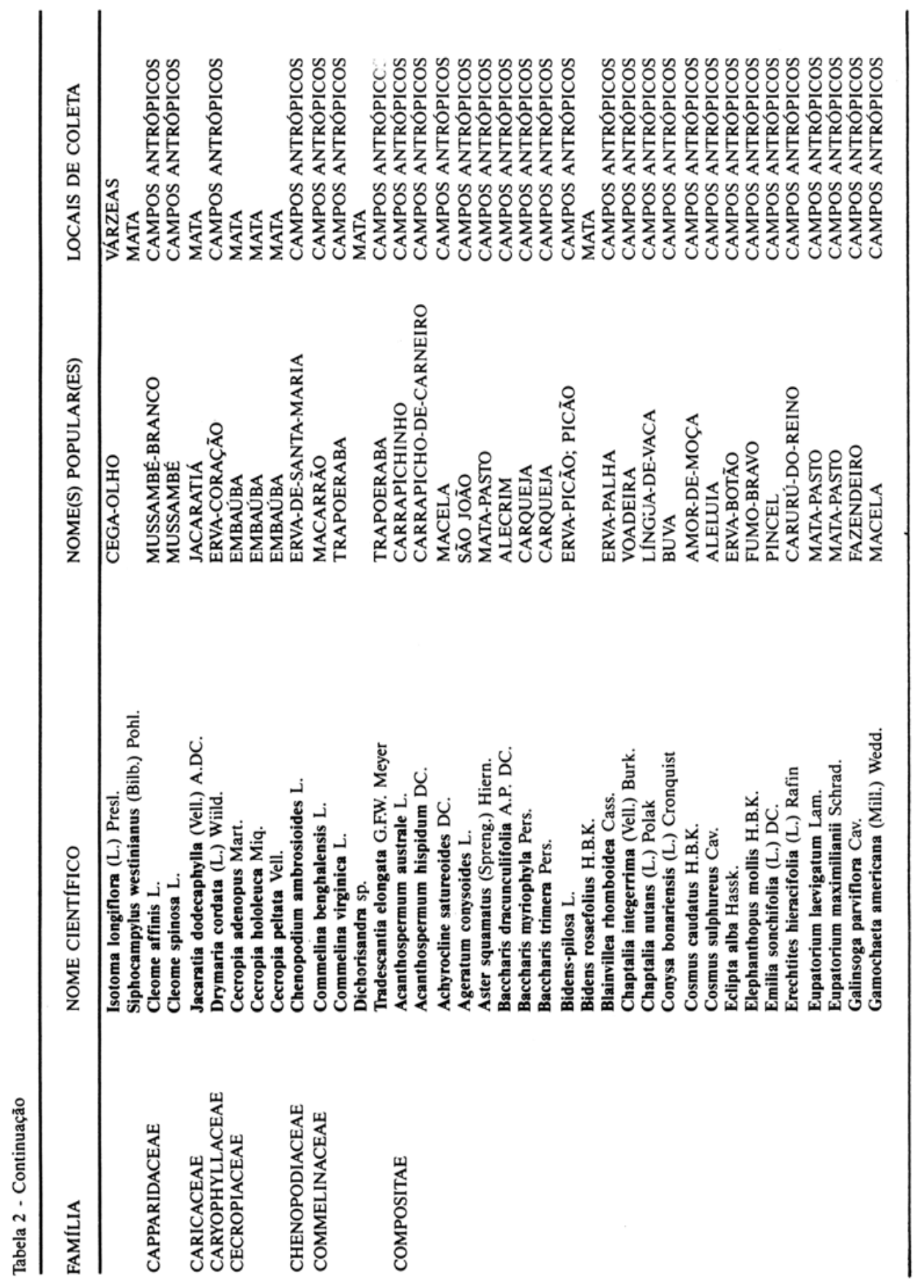




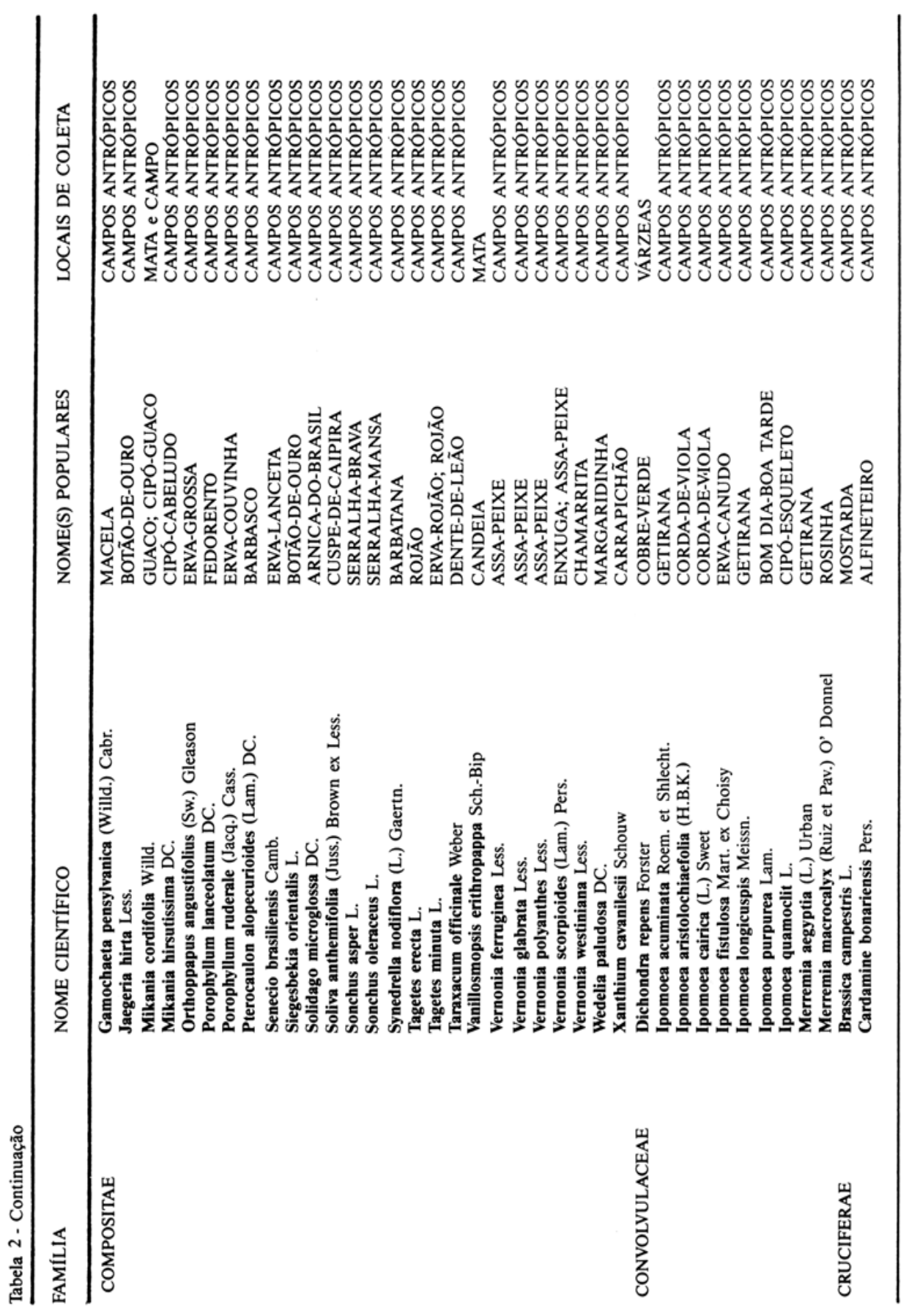




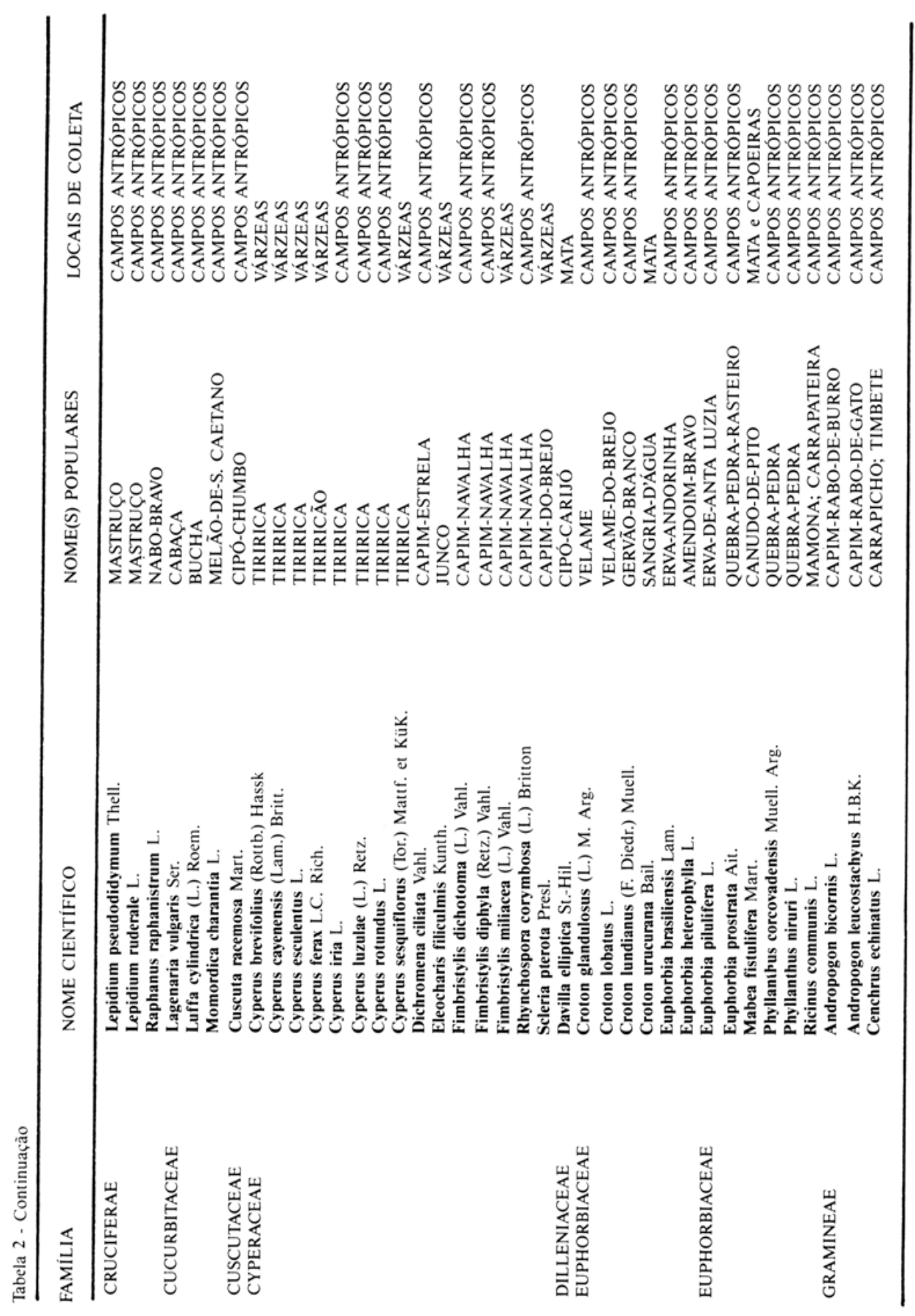




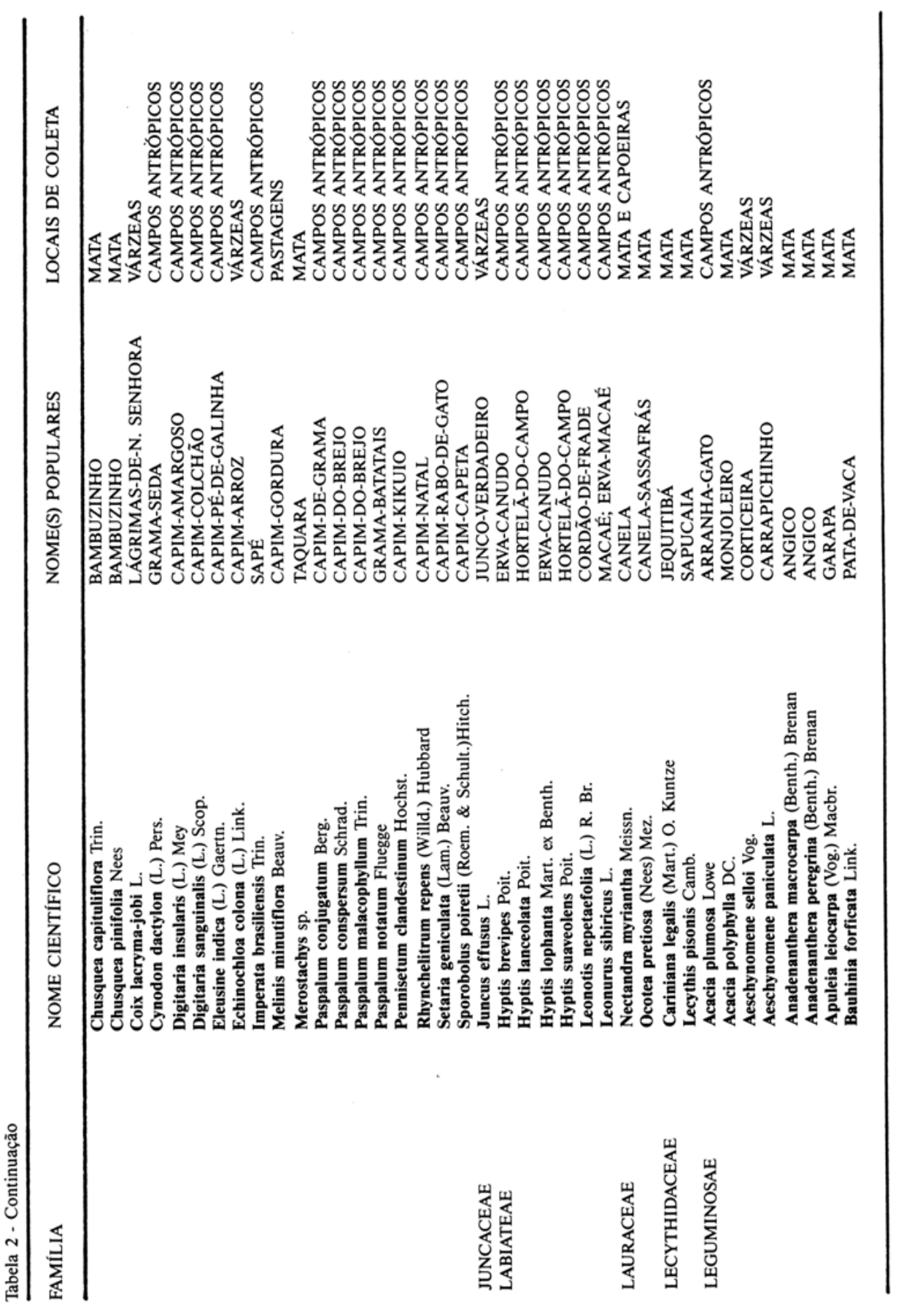




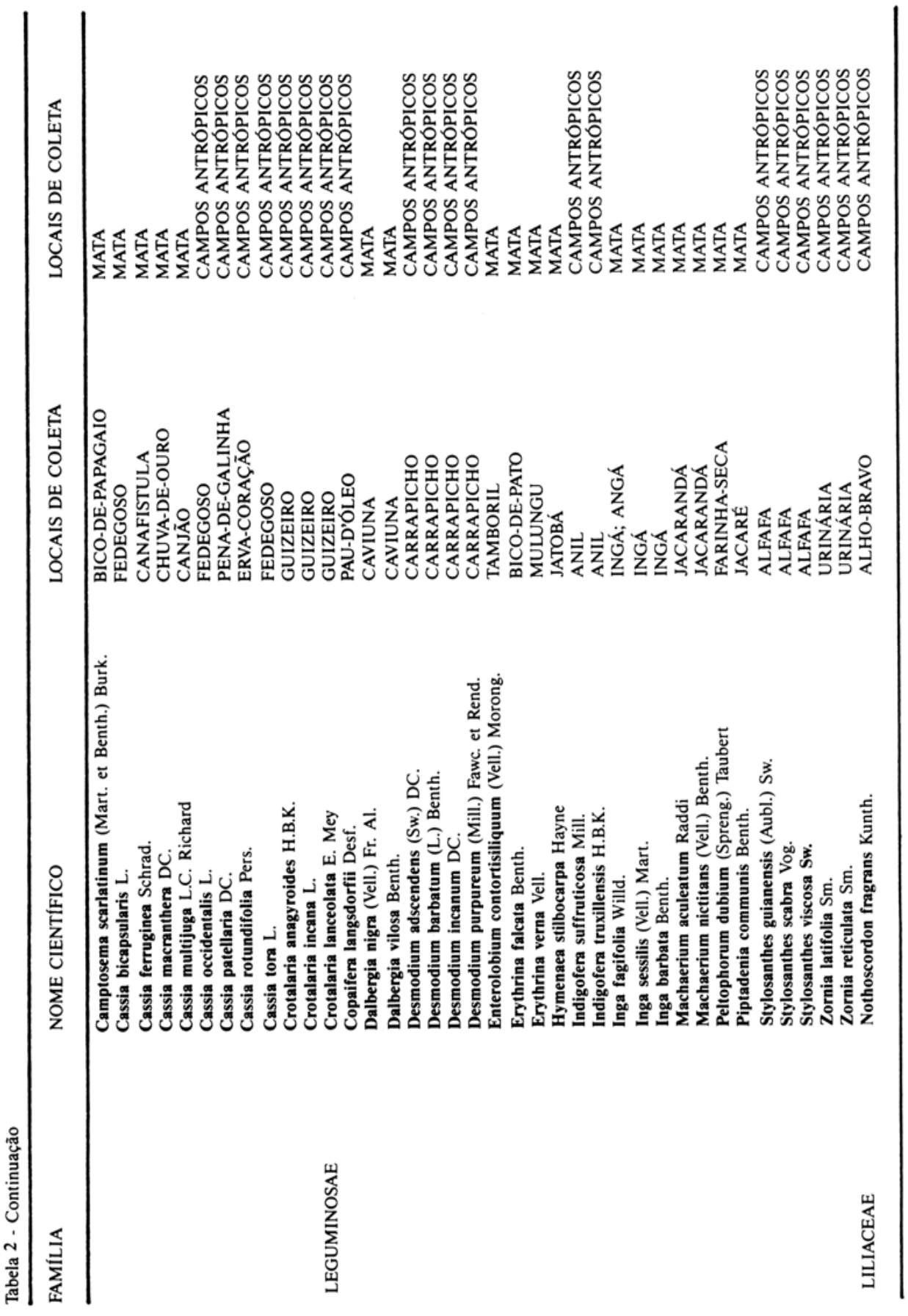




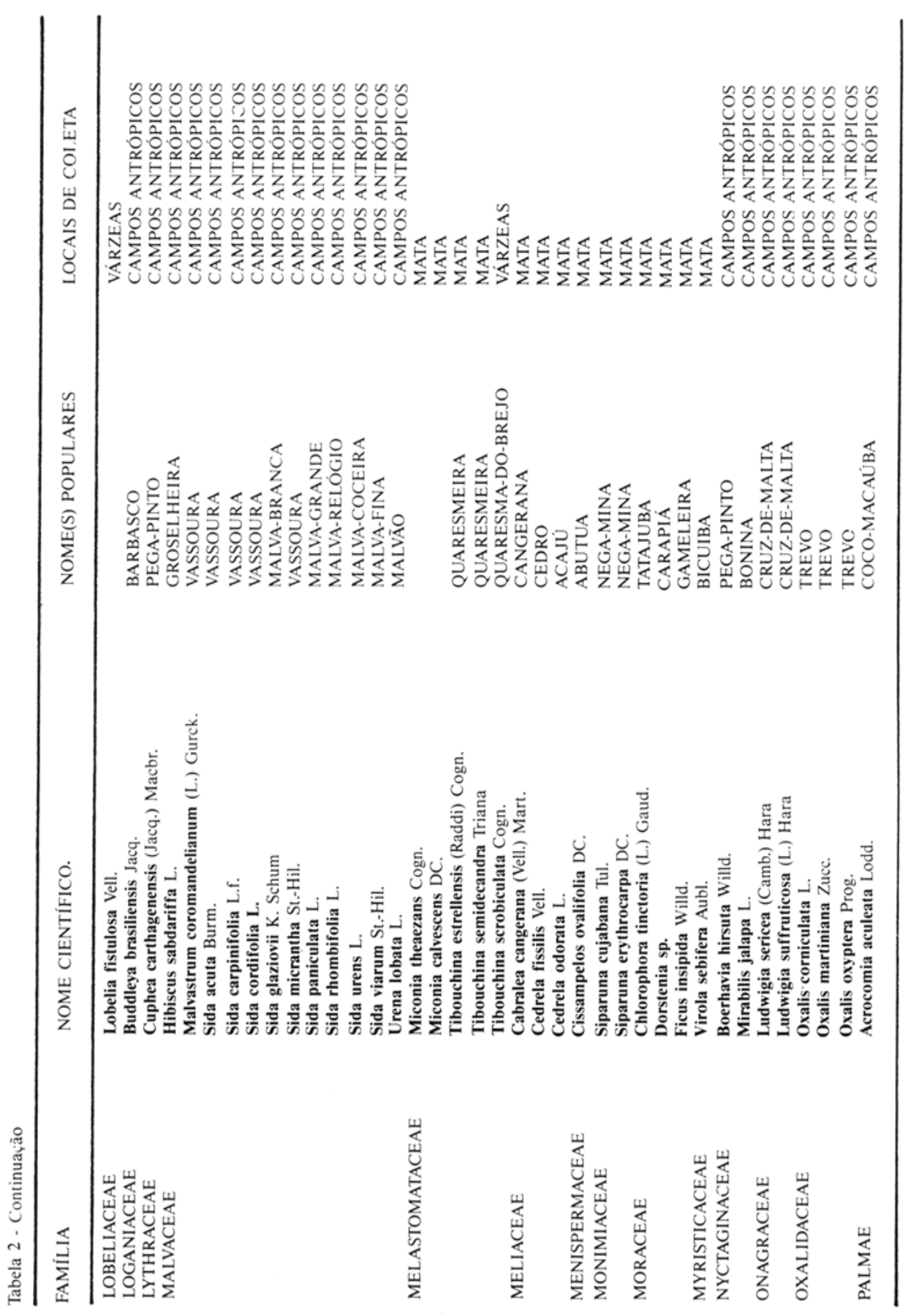




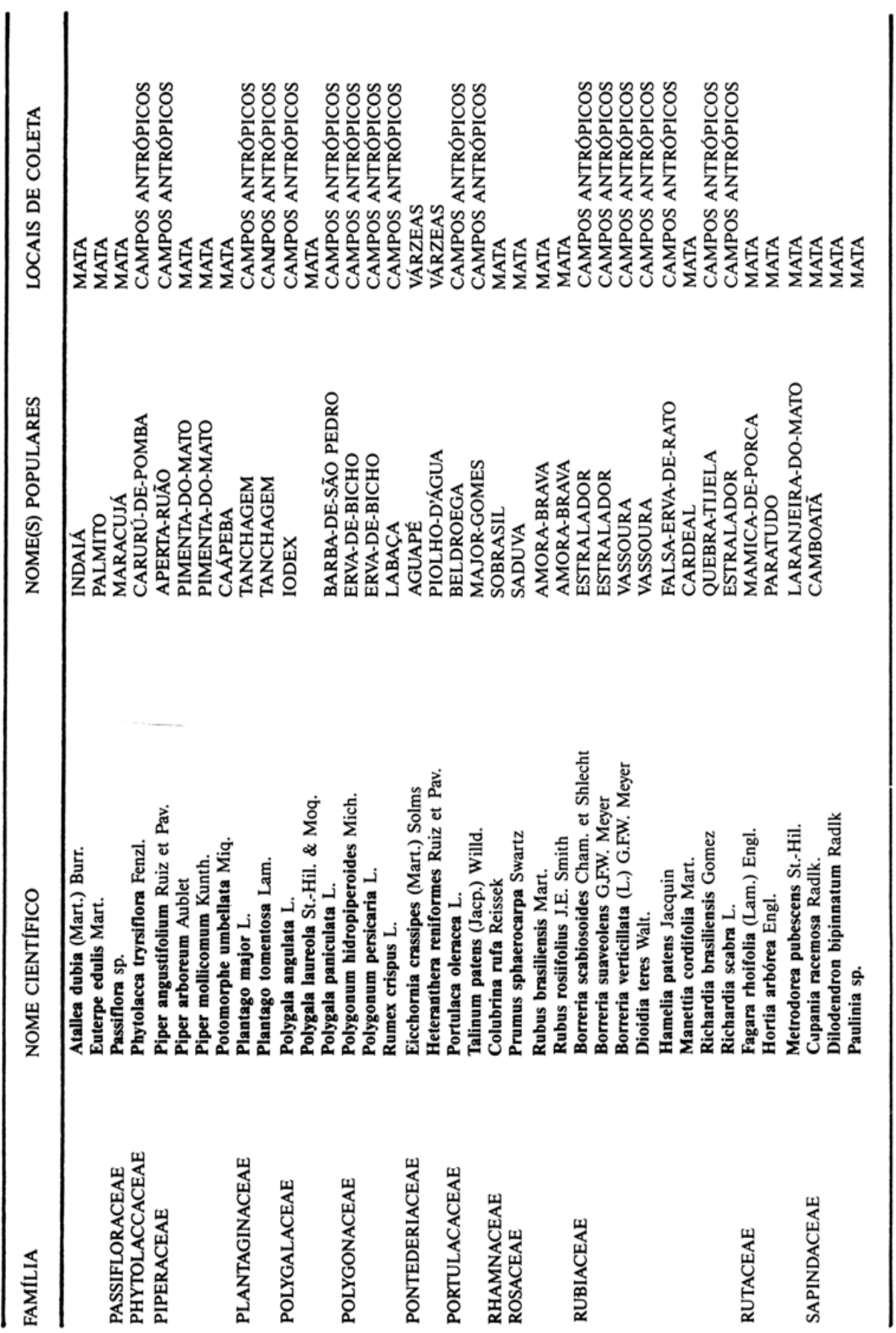




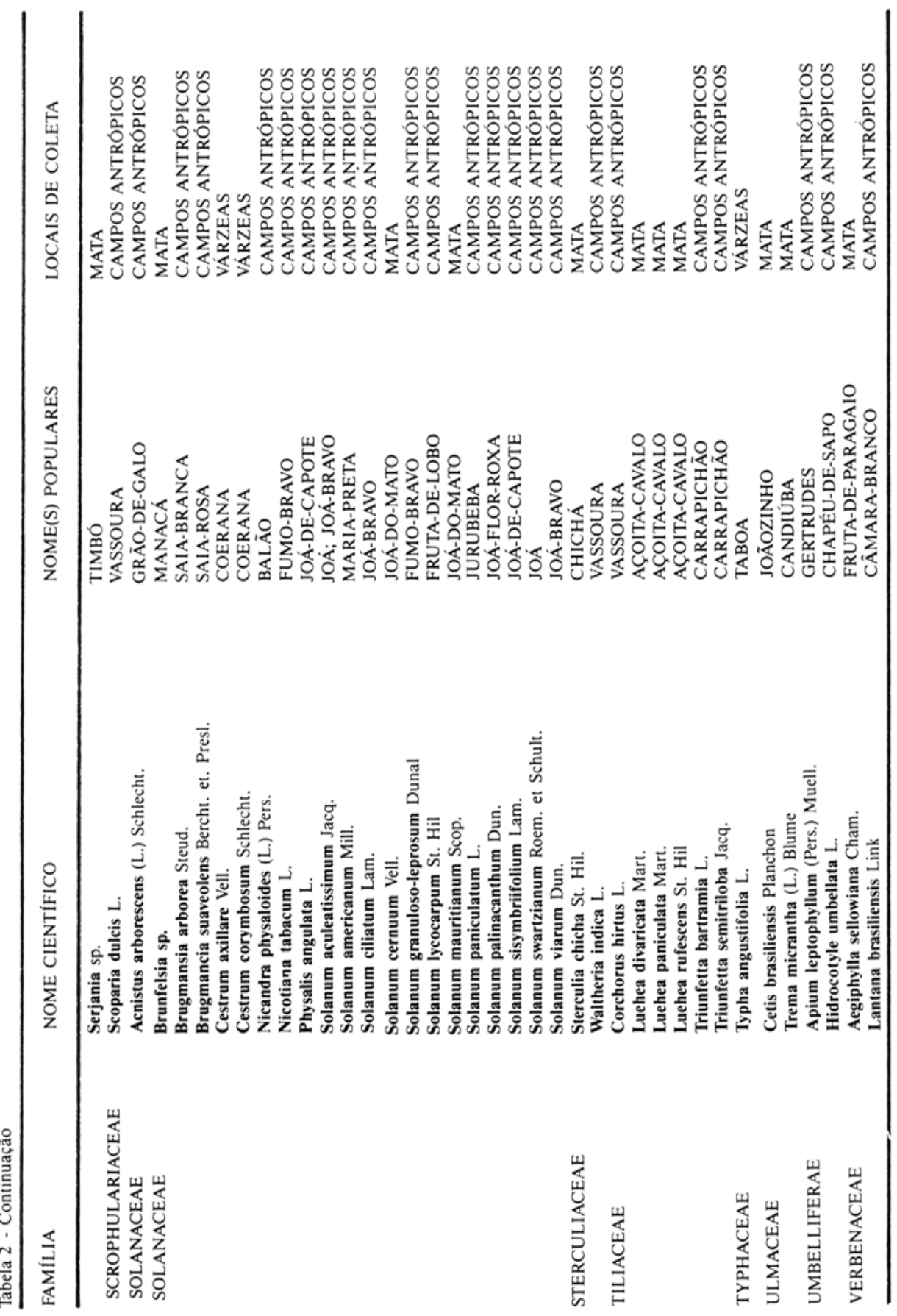




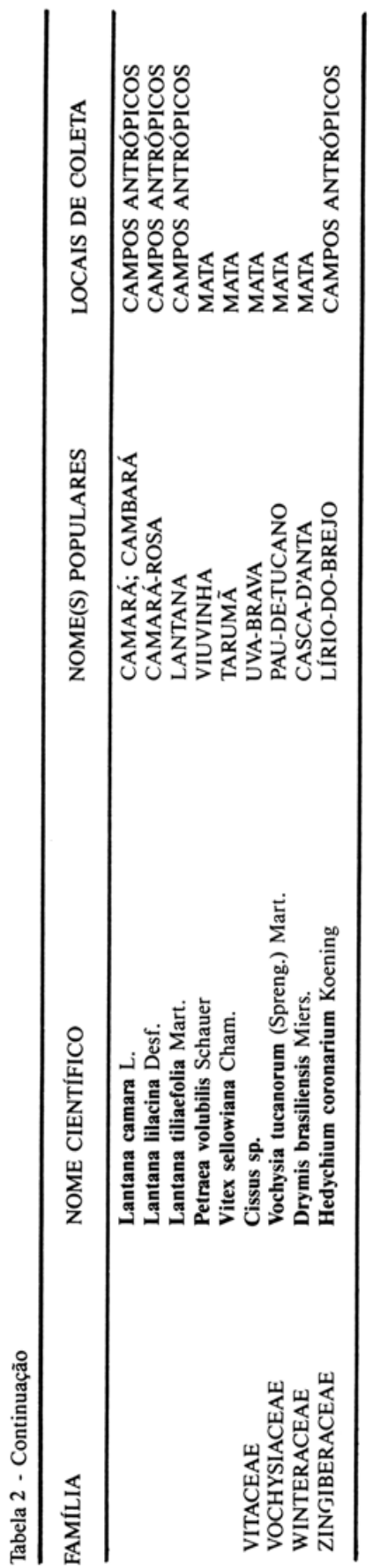

